\title{
An Innovative Approach for Water Distribution Systems
}

\author{
Van-Phuong Ta*, Dinh-Nhon Truong and Nguyen-Thanh Nhan
}

\author{
Ho Chi Minh City University of Technology and Education, Ho Chi Minh, 70000, Vietnam \\ *Corresponding Author: Van-Phuong Ta. Email: phuongtv@hcmute.edu.vn \\ Received: 05 August 2021; Accepted: 06 September 2021
}

\begin{abstract}
Water Distribution System (WDS) is one of the important phases of the Water Treatment Plant (WTP) and plays a crucial role in plant, animal, and human life. The WDS aims not only to supply a continuous, stable water amount but also to reduce energy consumption as little as possible during operation. To keep the continuous, stable water amount, the water pressure in the pipe network of the WDS must be maintained at desired set points under the effecting of uncertainties, disturbances, and noises. For saving the energy requirement, a Variable Frequency Driver (VFD) was utilized to control the speed of the Water Boost Pump (WBP) as speed as the WDS requires and a Recurrent Cerebellar Model Articulation Control System (RCMACS) was proposed to keep the water pressure at desired reference under abnormal events. Furthermore, to adapt to the industrial environment, the RCMACS was implemented on the Allen-Bradly Programmable Logic Controller (PLC), and industrial networks were also proposed to connect and transfer data between control stations and field devices.
\end{abstract}

Keywords: Water distribution system (WDS); cerebellar model articulation controller (CMAC); compensator controller; variable frequency driver; programmable logic controller; industrial networks

\section{Introduction}

The Water Distribution System (WDS) plays an important role in plant, animal, and human life [1]. Due to its continuous operation, the WDS guarantees not only a continuous, stable, and quality water amount to meet the demands of customers but also to reduce electrical energy consumption as little as possible during operation. According to the structure of the WDS, guaranteeing the continuous, stable, and water amount for reality demands can be done by keeping the pressure in the water pipe system at desired set points under the presence of uncertainties such as uncertain water consumption, uncertain current, the friction coefficient of the pipe, valve status, and so on [2-5]. Due to the effect of many uncertainties, the stability of the pressure in the pipe is a very difficult task [6,7]. To achieve stability of control systems, the Proportional Integral Derivative (PID) controller has been developed and applied in many applications $[8,9]$. However, the influences of the uncertainties, disturbance, and noises, the dynamic model of the practical systems are hardly be established [10]. Consequently, model-based controllers such as the PID can't obtain desired performances [11-14].

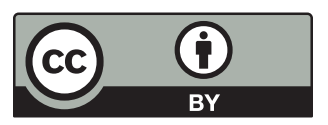

This work is licensed under a Creative Commons Attribution 4.0 International License, which permits unrestricted use, distribution, and reproduction in any medium, provided the original work is properly cited. 
Neural networks (NNs) can approximate non-linear functions to arbitrary precision by learning ability Therefore, it has been proposed to cope with uncertainty systems and obtained good results in realistic applications [15-17]. However, weights of the NNs are updated in each learning cycle, this is not suitable for applications requiring online learning. Furthermore, the selection of the number of neurons and hidden layers to achieve good performances is usually obtained by trial and error.

To improve the learning ability of the NNs in real-time, the Recurrent Cerebellar Model Articulation Controllers (RCMAC) have been developed and applied for uncertain, non-model, and non-linear systems $[18,19]$. The effectiveness of the RCMAC in controlling practical applications have achieved good responses [20,21].

Although the RCMAC can deal with uncertain systems to achieve desired performances. However, the implementation of this controller for industrial applications has not been widespread. Consequently, implementing the RCMAC on the Programmable Logic Controller (PLC) to stabilize the water pressure for the WDS is one of the aims of this work.

Along with archiving the water pressure stability for the WDS, saving energy has been also extremely important. For the WDS, the highest energy consumption comes from the WBP. To reduce the energy consumption of the WBP, a VFD was utilized to control the speed of the WBP. By using the VFD, the WBP was supplied only enough energy to meet demand. Therefore, it can be considered as a very effective control method for the WBP to save energy. From the point of view of the stability, robustness, and saving energy for the WDS, this article proposed a recurrent cerebellar model articulation control system (RCMACS) to maintain the pressure in the water pipe system at desired set points. Besides the VFD was utilized to control the WBP for saving energy. With this solution, not only the persistence of the system was guaranteed but also the energy consumption was decreased significantly comparing with the non-VFD solution [22]. Furthermore, to adapt to the industrial environment, the control system was implemented on an industrial programmable logic controller (PLC) of Rockwell Automation and industrial network solutions were also utilized to connect and transfer data between the control stations and field devices $[23,24]$.

The rest of this paper is organized as follows: Section 2 presents the structure of the WDS and the proposed control system. Section 3 describes designing of the proposed control system. The experimental results were shown in Section 4 and Section 5 is the conclusions and suggestions for the next works

\section{Introduction the Water Distribution System and Proposed Control System}

\subsection{The Structure of the Water Distribution System}

The Water Distribution System (WDS) is one of the important phases in the Water Treatment Plant (WTP). There are many different models of the WDS in the WTP. In this article, the structure of the WDS is described in Fig. 1. The WDS is a remote station that contains a ControlNet Module CNB2 to connect to the central station by ControlNet Network, a DeviceNet Module DNB to connect to the VFD by DeviceNet Network. The VFD is used to control the WBP to supply clean water to customers continuously and stably at desired set points; the pressure in the pipe was measured by a pressure transmitter (PT) then the PT's signal was fed to the VFD and sent back to the central station via the DeviceNet Network and ControlNet Network. The central station which contains a ControlLogix L71, an Ethernet Module EN2T, and a ControlNet Module CNB receives the pressure value (PV) from the PT and the setpoints from PC or HMI to manipulate controlled variables by the RCMACS before sending the signal control to the VFD via the ControlNet and DeviceNet Network. 


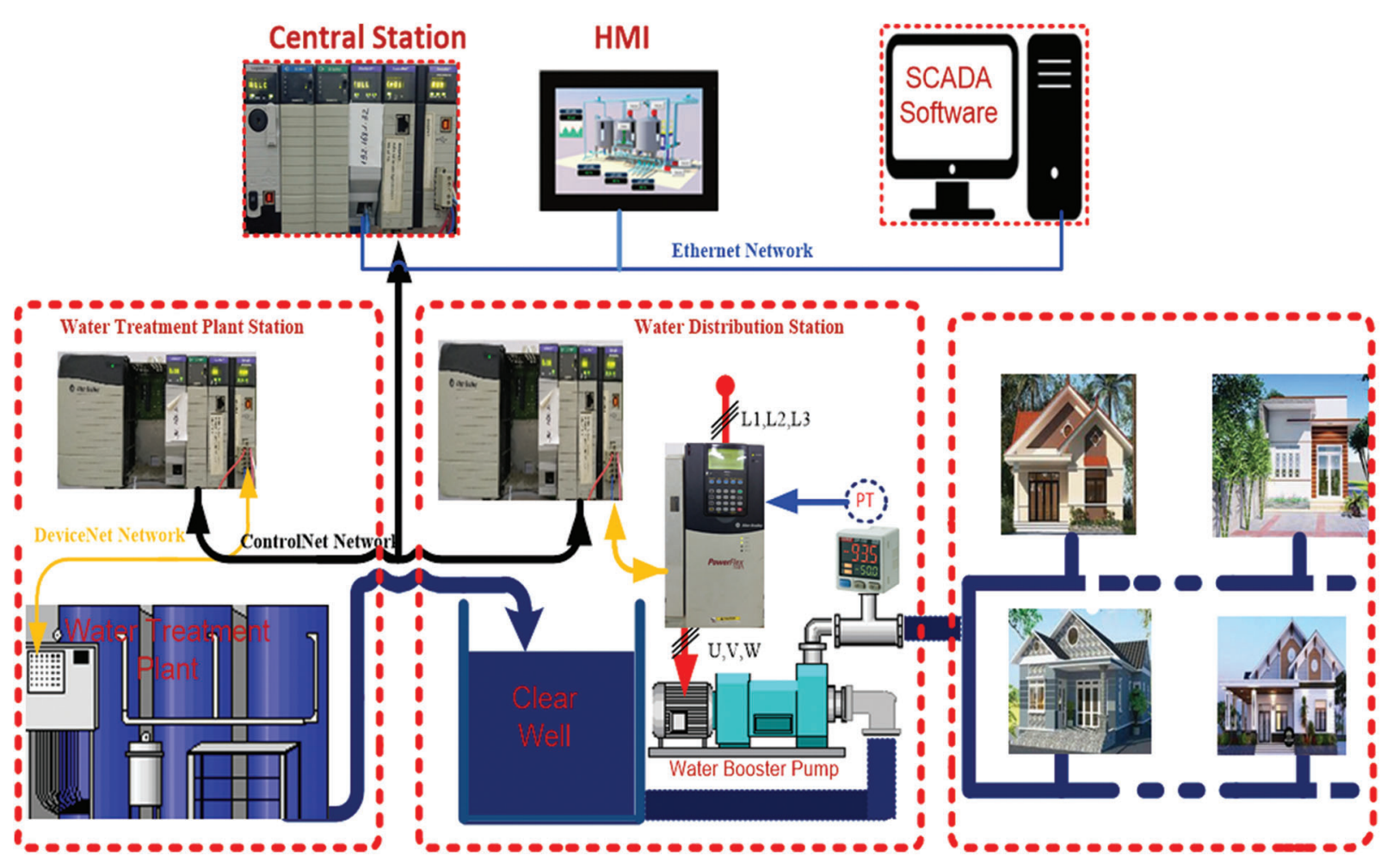

Figure 1: Experimental structure of the water distribution system

\subsection{The Proposed Control System}

The dynamic model of practical industrial applications is extremely difficult to define. In this research, the dynamic equation of the pressure in the water pipe of the WDS was identified by the Matlab tool. The linearized dynamic model under the effects of uncertainties, disturbances, and non-linear parts is given as bellow

$\ddot{y}=-0.043 \dot{y}-0.0012 \mathrm{y}-\mathrm{udn}+0.01 \mathrm{u}$

where $\mathrm{u}$ and $\mathrm{y}$ are the control signal and the pressure in the water pipe. $u d n$ stands for uncertainties, disturbances, and noises.

To reduce the order of the dynamic equation, the sliding error surface was defined and used during designing and computing the control system [25]. The sliding error surface has the following form

$\mathrm{S}=\dot{\mathrm{e}}+\mathrm{k}_{1} e+\mathrm{k}_{2} \int \mathrm{e}$

where $\mathrm{e}=\mathrm{y}_{\mathrm{d}}-\mathrm{y}$ is the error, $\mathrm{y}_{\mathrm{d}}$ is the desired pressure setpoint, and $\mathrm{S}=\dot{\mathrm{e}}+\mathrm{k}_{1} \mathrm{e}+\mathrm{k}_{2} \int \mathrm{e}$ is the error sliding surface of the system. Derivative both sides of $S$ and refer to the dynamic equation Eq. (1), yields

$$
\begin{aligned}
\dot{\mathrm{S}} & =\ddot{\mathrm{e}}+\mathrm{k}_{1} \dot{\mathrm{e}}+\mathrm{k}_{2} \mathrm{e} \\
& =\ddot{\mathrm{y}}_{\mathrm{d}}-\ddot{\mathrm{y}}+\mathrm{k}_{1} \dot{\mathrm{e}}+\mathrm{k}_{2} \mathrm{e} \\
& =\ddot{\mathrm{y}}_{\mathrm{d}}+\mathrm{a}_{1} 3 \dot{\mathrm{y}}+\mathrm{a}_{2} \mathrm{y}+\mathrm{udn}+b_{0} \mathrm{u}+\mathrm{k}_{1} \dot{\mathrm{e}}+\mathrm{k}_{2} \mathrm{e}
\end{aligned}
$$

where $\mathrm{b}_{0}=0.01, \mathrm{a}_{1}=0.043, \mathrm{a}_{2}=0.0012$ 
In case of uncertainties, disturbances, and noise $u d n$ are exactly known, a nominal controller, $\mathrm{u}_{n o m}$ is designed to guarantee the stability of the system as follows [22].

$\mathrm{u}_{\mathrm{nom}}=\frac{1}{\mathrm{~b}_{0}}\left[\ddot{\mathrm{y}}_{d}-\mathrm{a}_{1} \dot{\mathrm{y}}-\mathrm{a}_{2} \mathrm{y}-\mathrm{udn}+\mathrm{k}_{1} \dot{\mathrm{e}}+\mathrm{k}_{2} \mathrm{e}\right]$

Replacing $u$ in (1) by $u_{\text {nom }}$ in (4), yields

$\ddot{\mathrm{e}}+\mathrm{k}_{1} \dot{\mathrm{e}}+\mathrm{k}_{2} \mathrm{e}=0$

If both coefficients of $\mathrm{k}_{1}$ and $\mathrm{k}_{2}$ are selected by the Routh-Hurwitz criterion, the stability of the system is guaranteed. However, for the WDS, the uncertainties, disturbances, and noise, udn, can't be measured or estimated exactly. Consequently, the stability and robustness of the system can't achieve by using only the $u_{\text {nom. }}$. To cope with this problem, a control system includes $u_{n o m}, u_{R C M A C}$, and $u_{C C}$ was proposed in Fig. 2. In this control system, the $\mathrm{u}_{\text {nom }}$ can stabilize the pressure in the pipe in case uncertainties, disturbances, and noise is non-existent. The RCMAC learns the uncertainties caused by non-linear parts and changes of parameters to minimize the error sliding surface and $\mathrm{u}_{\mathrm{CC}}$ maintains the pressure at set points under the effects of uncertainties, disturbances, and noise. The proposed control system is a combination of three terms as below.

$\mathrm{u}_{\mathrm{RCMACS}}=\mathrm{u}_{\mathrm{nom}}+\mathrm{u}_{\mathrm{RCMAC}}+\mathrm{u}_{\mathrm{CC}}$

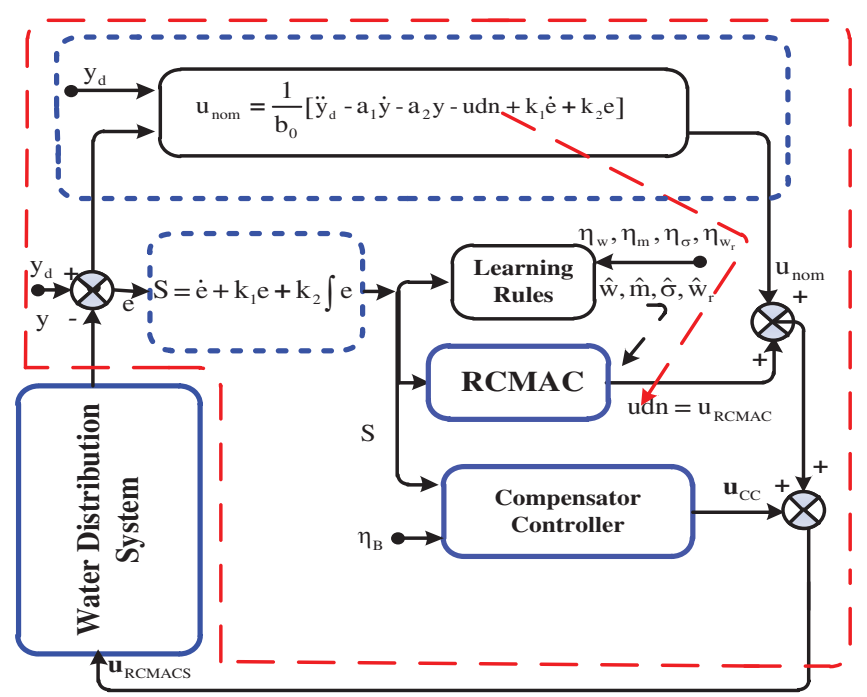

Figure 2: The proposed control system for the WDS

To adapt to the industrial environment, the RCMACS was implemented on the industrial ControlLogix L71 at the central station. The central station plays the principal role in data collecting, processing, and controlling the operation of all systems

\section{Designing the Proposed Control System}

\subsection{Structure of the RCMAC}

The $\mathbf{u}_{\mathrm{RCMAC}}$ aims to learn the uncertainties, $u d n$, due to the effects of uncertainties to minimize the sliding error surface [21]. The structure of the $R C M A C$ is shown in Fig. 3. It includes input Space $S$, association memory space $A$, receptive field space $R$, weight memory space $W$, and output spaces $O$ [26]. 
The data propagation from inputs to outputs of the RCMAC is described as bellow [21,26]

$\mathrm{S}_{\mathrm{ri}}(\mathrm{k})=\mathrm{S}_{\mathrm{i}}(\mathrm{k})+\mathrm{w}_{\mathrm{rik}} \mu_{\mathrm{ik}}(\mathrm{k}-1), \quad \mathrm{i}=1,2, \ldots, \mathrm{n}$

$\mu_{\mathrm{ik}}\left(\mathrm{S}_{\mathrm{ri}}\right)=\exp \left[-\frac{\left(\mathrm{S}_{\mathrm{ri}}-\mathrm{m}_{\mathrm{ik}}\right)^{2}}{\sigma_{\mathrm{ik}}^{2}}\right], \quad \mathrm{k}=1,2, \ldots, \mathrm{n}_{\mathrm{b}}$

$\mathrm{b}_{\mathrm{ik}}=\prod_{\mathrm{i}=1}^{\mathrm{n}} \mu_{\mathrm{ik}}\left(\mathrm{S}_{\mathrm{ri}}\right), \quad \mathrm{i}=1,2, \ldots, \mathrm{n}, \quad \mathrm{k}=1,2, \ldots, \mathrm{n}_{\mathrm{b}}$

$\mathrm{O}_{\mathrm{j}}=\mathrm{u}_{R C M A C}=\sum_{\mathrm{j}=1}^{\mathrm{n}_{0}} \sum_{\mathrm{k}=1}^{\mathrm{n}_{\mathrm{b}}} \mathrm{w}_{\mathrm{jk}} \prod_{\mathrm{i}=1}^{\mathrm{n}} \mu_{\mathrm{ik}}\left(\mathrm{S}_{\mathrm{ri}}\right)$

$=w^{T} \mathbf{b}, \quad \mathrm{j}=1,2, \ldots, \mathrm{n}_{0}$

wheren, $\mathrm{n}_{\mathrm{o}}$, and $\mathrm{n}_{\mathrm{b}}$ are the number of inputs, outputs, and layers; $\mathrm{S}_{\mathrm{r}}, \mu, \mathrm{b}$, and $\mathrm{O}$ are the inputs, membership function, receptive space, and outputs respectively; $m$ and $\sigma$ are mean and deviation of membership function; $\mathrm{w}_{\mathrm{r}}$ and $\mathrm{w}$ are recurrent and output weights.

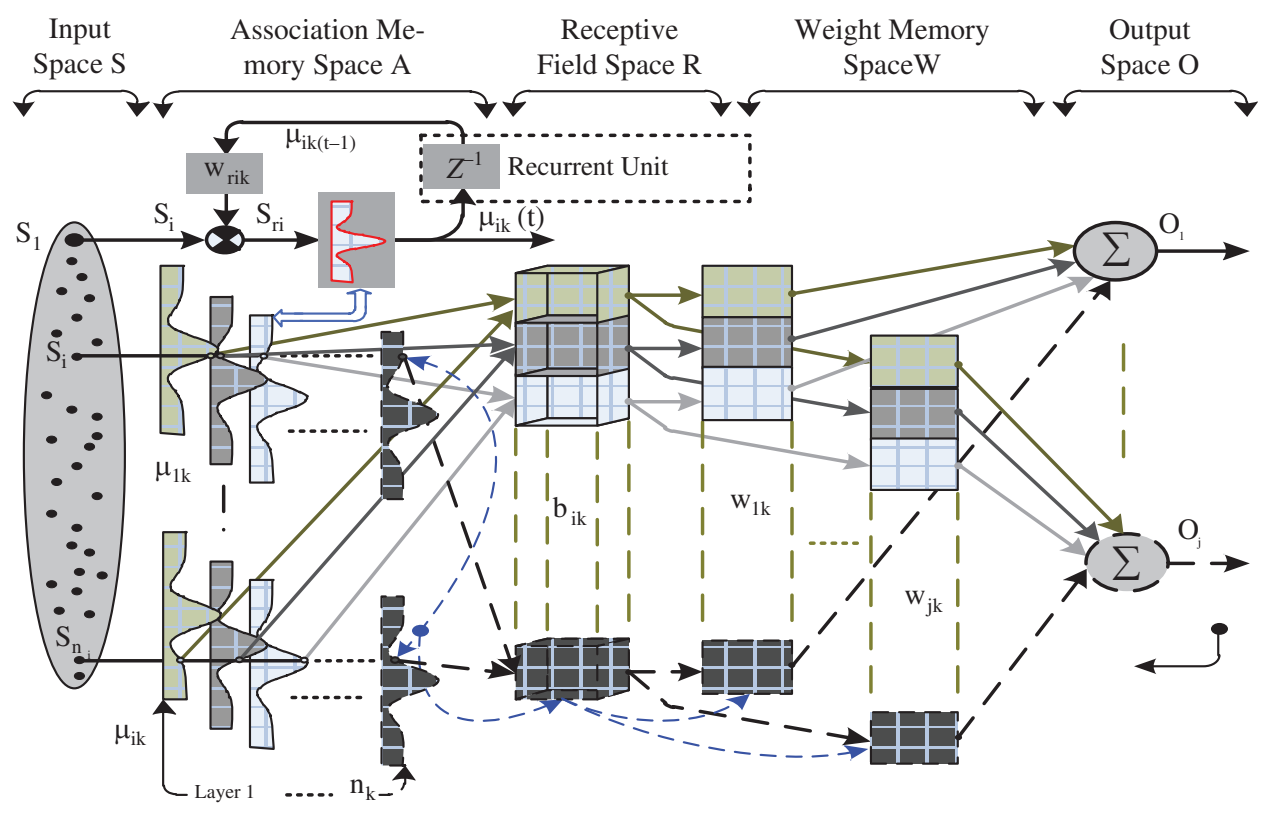

Figure 3: The structure of the RCMAC

\subsection{Learning Rules of the RCMAC}

In this research, $V(s)=\frac{1}{2} S^{2}$ is selected as an error function, $\dot{V}(s)=S \dot{S}$, the RCMAC turns the parameters to converge $V(s)=\frac{1}{2} S^{2}$ by minimizing $\dot{V}(s)$. Refer to Eqs. (1)-(4) yields

$$
\begin{array}{r}
\mathrm{SS}=\mathrm{S}\left(\ddot{e}+\mathrm{k}_{1} \dot{e}+\mathrm{k}_{2} e\right)=\mathrm{S}\left(\ddot{\mathrm{y}}_{d}-\ddot{\mathrm{y}}+\mathrm{k}_{1} \dot{e}+\mathrm{k}_{2} e\right)=\mathrm{S}\left(\mathrm{a}_{1} \mathrm{y}+\mathrm{a}_{2} \mathrm{y}\right)-\frac{1}{b_{0}} \mathrm{~S}\left(\mathrm{u}_{n o m}+\mathrm{u}_{R C M A C}+\mathrm{u}_{C C}\right) \\
+\mathrm{S}\left(\ddot{\mathrm{y}}_{d}-u d n+\mathrm{k}_{1} \dot{e}+\mathrm{k}_{2} e\right)
\end{array}
$$


According to the back-propagation algorithm, the parameters $\Delta \mathrm{w}_{\mathrm{kj}}, \Delta \mathrm{m}_{\mathrm{ik}}, \Delta \sigma_{\mathrm{ik}}$, and $\Delta w_{r i k}$ are turned to decrease the error function by the following rules

$$
\begin{aligned}
& \Delta \mathrm{w}_{\mathrm{kj}}=-\eta_{\mathrm{w}} \frac{\partial \mathrm{SS}}{\partial \mathrm{w}_{\mathrm{kj}}}=-\eta_{\mathrm{w}} \frac{\partial \mathrm{SS}}{\partial \mathbf{u}_{\mathrm{RCMAC}}} \frac{\partial \mathbf{u}_{\mathrm{RCMAC}}}{\partial \mathrm{w}_{\mathrm{kj}}}=\eta_{\mathrm{w}} \mathrm{S} \frac{1}{b_{0}}\left(\prod_{\mathrm{i}=1}^{\mathrm{n}_{\mathrm{i}}} \mu_{i k}\left(\mathrm{~S}_{\mathrm{ri}}\right)\right) \\
& \Delta \mathrm{m}_{\mathrm{ik}}=-\eta_{\mathrm{m}} \frac{\partial \mathrm{SS}}{\partial \mathrm{m}_{\mathrm{ik}}}=-\eta_{\mathrm{m}} \frac{\partial \mathrm{SS}}{\partial \mathbf{u}_{\mathrm{RCMAC}}} \frac{\partial \mathbf{u}_{\mathrm{RCMAC}}}{\partial \mu_{\mathrm{ik}}} \frac{\partial \mu_{\mathrm{ik}}}{\partial \mathrm{m}_{\mathrm{ik}}}=\eta_{\mathrm{m}} \mathrm{S} \frac{1}{b_{0}} \mathrm{w}_{\mathrm{kj}} 2 \frac{\left(S_{r i}-m_{i k}\right)}{\sigma_{i k}^{2}} \\
& \Delta \sigma_{\mathrm{ik}}=-\eta_{\sigma} \frac{\partial \mathrm{SS}}{\partial \sigma_{\mathrm{ik}}}=-\eta_{\sigma} \frac{\partial \mathrm{SS}}{\partial \mathbf{u}_{\mathrm{RCMAC}}} \frac{\partial \mathbf{u}_{\mathrm{RCMAC}}}{\partial \mu_{\mathrm{ik}}} \frac{\partial \mu_{\mathrm{ik}}}{\partial \sigma_{\mathrm{ik}}}=\eta_{\sigma} \mathrm{S} \frac{1}{b_{0}} \mathrm{w}_{\mathrm{kj}} 2 \frac{\left(S_{r i}-m_{i k}\right)^{2}}{\sigma_{i k}^{3}} \\
& \Delta w_{r i k}=-\eta_{w_{r i k}} \frac{\partial \mathrm{SS}}{\partial w_{r i k}}=-\eta_{w_{r i k}} \frac{\partial \mathrm{SS}}{\partial \mathbf{u}_{\mathrm{RCMAC}}} \frac{\partial \mathbf{u}_{\mathrm{RCMAC}}}{\partial \mu_{i k}} \frac{\partial \mu_{i k}}{\partial S_{r i}} \frac{\partial S_{r i}}{\partial w_{r i k}}=\eta_{w_{r i k}} \mathrm{~S} \frac{1}{b_{0}} \mathrm{w}_{\mathrm{kj}} 2 \frac{\left(S_{r i}-m_{i k}\right)}{\sigma_{i k}^{2}} \mu_{i(k-1)}
\end{aligned}
$$

\subsection{The Compensator Controller}

As the error sliding surface converges to zero, the compensator controller aims to maintain the system at this state under the effects of disturbances and noises. To achieve this target, a sliding mode control-based compensator controller can be designed as below

$\mathrm{u}_{c c}=\frac{1}{b_{0}} \hat{B} \operatorname{sign}(S)$

where $B$ is the error boundary and $\hat{B}$ is an estimation of $B$. The error boundary of disturbances and noises cannot be exactly measured. Furthermore, to reduce the output chattering phenomenon, the error boundary was estimated instead of the pre-fixed value. The estimate rule was selected as bellow [21].

$\widehat{B}=\eta_{\mathrm{B}}\|\mathrm{S}\|$

According to the sense of Barbalat's Lemma [27,28], the estimating rule given in Eq. (16) guarantees the robustness of the system.

\subsection{The Industrial Communication Network Solutions}

Industrial automation systems need many sensors, actuators, remote stations, and a large industrial space. In these systems, noise, disturbances, and signal attenuation problems affect significantly the performance of the system [29]. To cope with these problems, industrial network solutions have been developed to connect and transfer data between the central control station and field devices [30]. Fig. 4 presents industrial networks that have been developed by Rockwell Automation.

Depend on the number of sensors, actuators, distance, baud rates, engineers can choose a suitable industrial network. The specifications of DeviceNet Network, ControlNet Network, and Ethernet Network of Rockwell Automation were given in Tab. 1

\section{Experimental Results}

An image of the practical workbench of the WDS is shown in Fig. 5. The major devices of the experiment include a Central Station, Water Distribution System (WDS) station, a Pressure Transmitter (PT), a Variable Frequency Drive (VFD), a Water Boost Pump (WBP), Pressure Tanks, and Storage Tank.

The central station is installed a ControlLogix L71, an Ethernet Module EN2T, and a ControlNet Module CNB2. The WDS is installed a ControlNet Module CNB2, a Device Module DNB. 


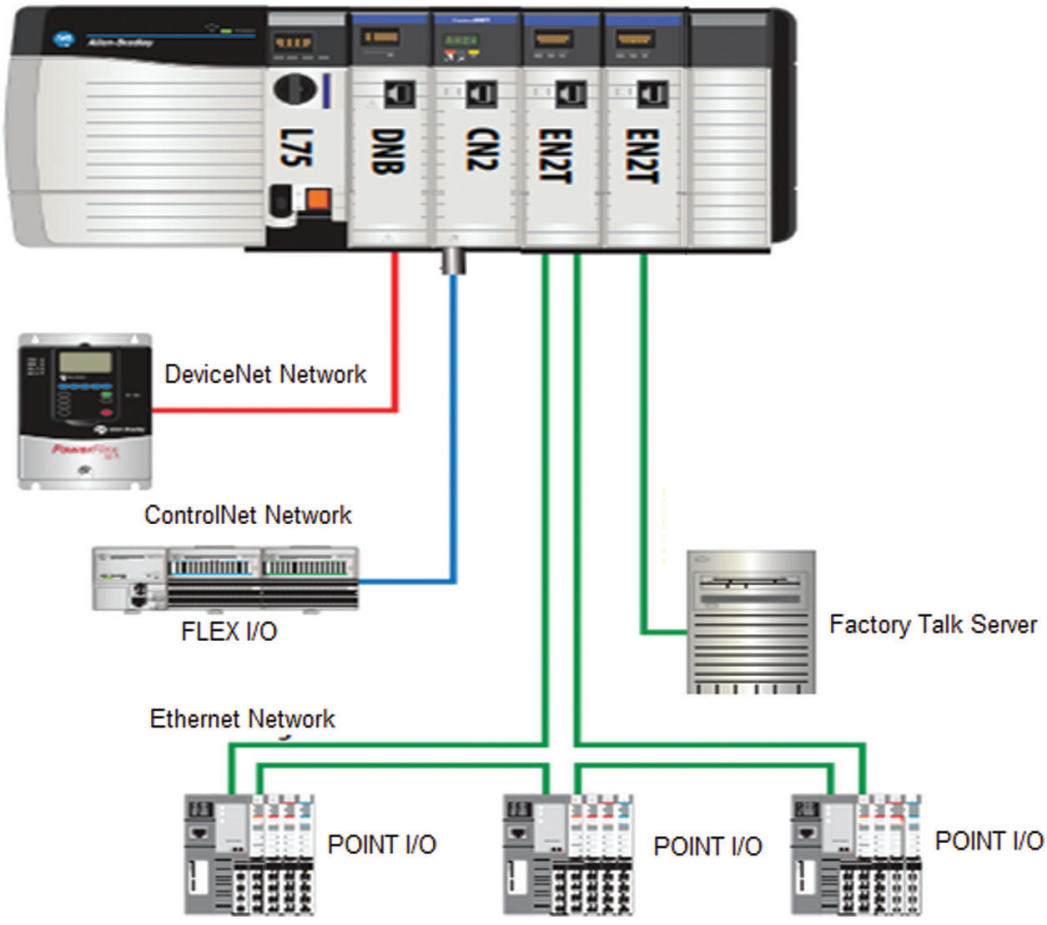

Figure 4: Industrial network solutions of rockwell automation

Table 1: Specifications of industrial networks

\begin{tabular}{|c|c|c|c|}
\hline Specifications & DeviceNet & ControlNet & Ethernet \\
\hline $\begin{array}{l}\text { Network size } \\
\text { (nodes) }\end{array}$ & Up to 64 & Up to 99 & No limit \\
\hline Baud rates & $125,250,512 \mathrm{Kbps}$ & $5 \mathrm{Mbps}$ & Up to $1 \mathrm{Gbps}$ \\
\hline Data transfer & $\begin{array}{l}\text { Large packets transfer } \\
\text { regularly }\end{array}$ & $\begin{array}{l}\text { Medium packets, cyclic, and } \\
\text { acyclic }\end{array}$ & $\begin{array}{l}\text { Small packet, data send as } \\
\text { needed }\end{array}$ \\
\hline Bus topology & $\begin{array}{l}\text { Linear (Trunkline/ } \\
\text { Dropline) }\end{array}$ & $\begin{array}{l}\text { Token ring, token passing- } \\
\text { bus }\end{array}$ & Star, ring \\
\hline
\end{tabular}

The connection between the central station and the WDS is carried out by the ControlNet Network, the WDS connects to the VFD by DeviceNet Network. PT is connected to the analog input of the VFD and data of the PT is transferred to the WDS by the DeviceNet Network. The WBP is controlled by the Drive to achieve the desired speed depending on the setpoint of pressure in the pipe.

The controllers, network modules, and the VFD are produced by Rockwell Automation. The control algorithms were programmed and embedded in the ControlLgoix L71 at the central station. To prove the effectiveness of the RCMACS in real-time, a PID controller was also used to control the system with the same setpoints with the RCMACS, both the PID controller and the RCMACS were implemented on the ControlLogix L71 at the central station. 


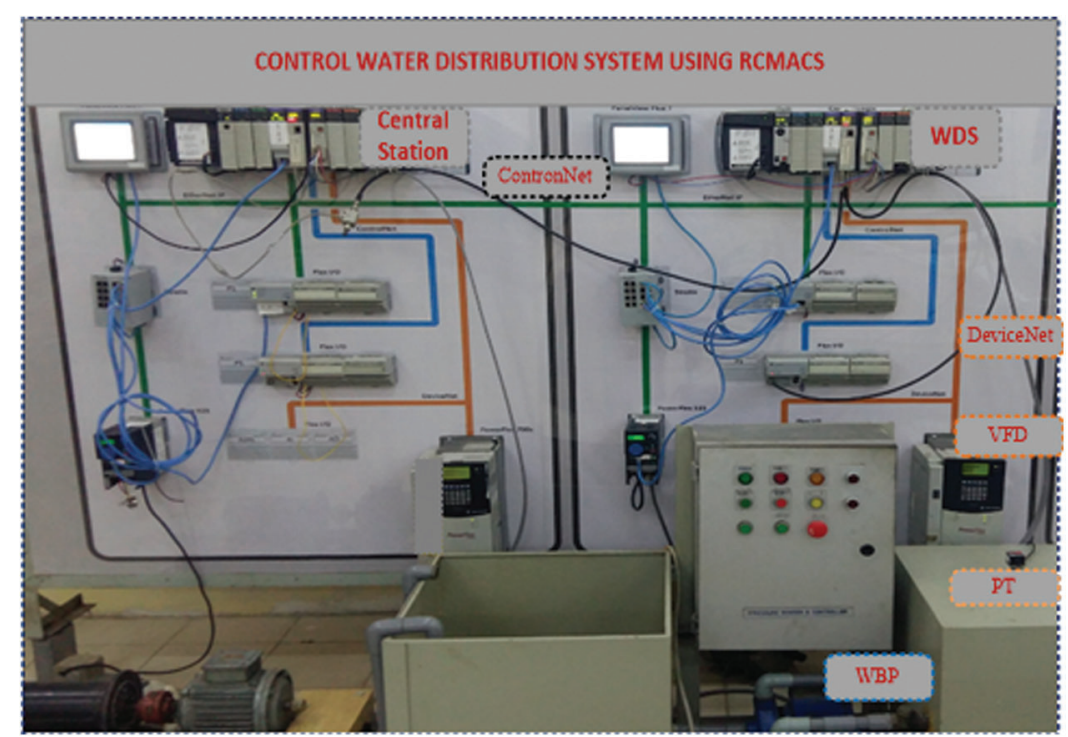

Figure 5: Image of the practical workbench of the WDS

The initial parameters of the RCMACS were given as bellow

$$
\begin{aligned}
& \eta_{w}=\eta_{m}=\eta_{\sigma}=\eta_{w r}=\eta_{B}=0.0015, \quad n=n_{0}=1, \quad n_{b}=9, \quad k_{1}=9.32, \quad k_{2}=0.02
\end{aligned}
$$

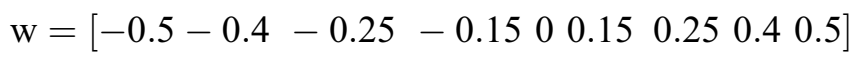

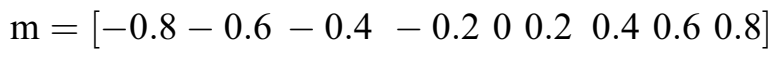

$$
\begin{aligned}
& \sigma=\left[\begin{array}{lllllllll}
0.3 & 0.3 & 0.3 & 0.3 & 0.3 & 0.3 & 0.3 & 0.3 & 0.3
\end{array}\right]
\end{aligned}
$$

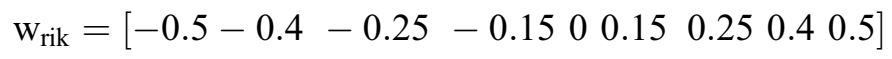

The tracking and error responses of the pressure in the water pipe with step commands for the RCMACS and PID controller were represented in Figs. 6 and 7, respectively.

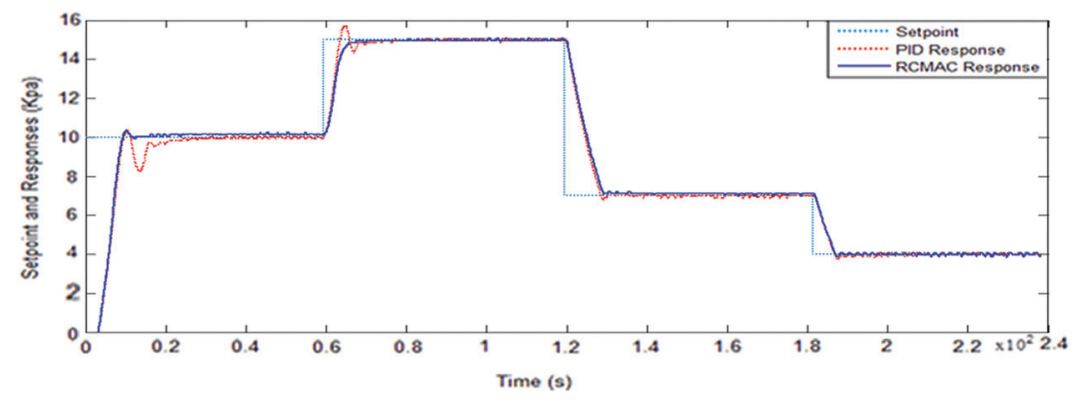

Figure 6: Tracking response of the pressure in the pipe with step commands

The experiment results showed that the RCMACS can achieve stability and robustness for the WDS. Compare to the PID controller, the RCMACS has better performances in setting time, overshoot, and error. The performances of the RCMACS and PID controller were also represented in detail in Tab. 2. 


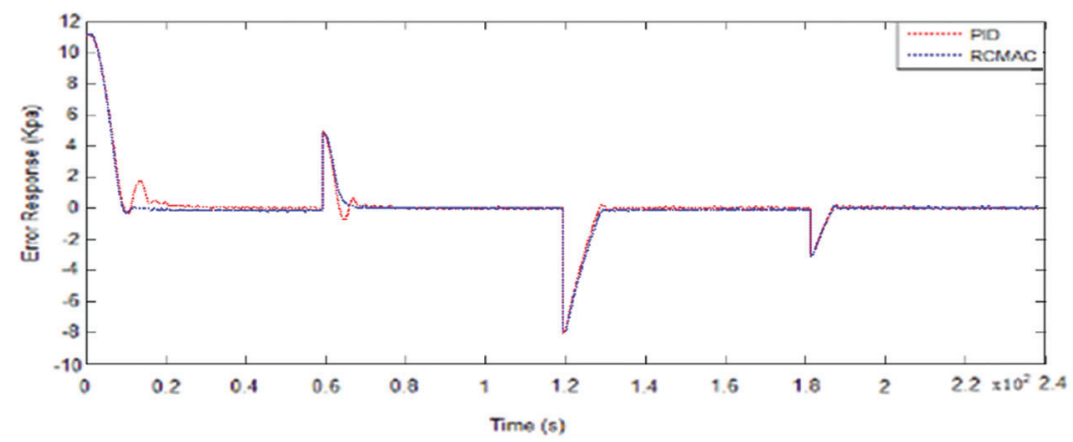

Figure 7: Error Response of the pressure in the pipe with step commands

Table 2: Performances of the PID and the RCMACS for the WDS

\begin{tabular}{lll}
\hline Performances & PID & RCMACS \\
\hline Setting time (s) & 20 & 13 \\
Overshoot (\%) & 4.7 & 0 \\
Error (\%) & $0-1.8$ & $0-0.7$ \\
\hline
\end{tabular}

\section{Conclusion and Next Researches}

In this work, the WDS is controlled successfully by the RCMACS in real-time under the presence of uncertainties, external disturbances, and noise, $u d n$.

The experimental results of the WDS proved the effectiveness of the proposed control system. Furthermore, the existent of uncertainties, non-linear, disturbances, and noises of the practical industrial applications firmly occur. Therefore, the proposed control system can be deployed to other practical applications.

By implementing the RCMACS on the industrial controller ControlLogix L71 and utilizing the industrial network solutions, the proposed control system is suitable for practical industrial applications. However, the control system should be implemented for fault detection and diagnosis during the operation of the system in the next works.

Acknowledgement: This research is supported by Ho Chi Minh City University of Technology and Education (HCMUTE), Vietnam.

Funding Statement: The authors have received funding support by Ho Chi Minh City University of Technology and Education (HCMUTE), Vietnam.

Conflicts of Interest: The authors declare that they have no conflicts of interest to report regarding the present study.

\section{References}

[1] A. Kumar, K. Kumar, B. Bharanidharan, N. Matial, E. Dey et al., "Designing of water distribution system using EPANET," International Journal of Advanced Research, vol. 3, no. 9, pp. 789-812, 2015.

[2] Z. S. Kapelan, D. A. Savic and G. A. Walters, "Multiobjective design of water distribution systems under uncertainty," Water Resource Research, vol. 41, no. 11, pp. 1-15, 2005. 
[3] P. F. Boulos, B. W. Karney, D. J. Wood and S. Lingireddy, "Hydraulic transisten guidelines for protecting water distribution system," Journal American Water Work Association, vol. 97, no. 5, pp. 111-124, 2005.

[4] G. Galuppini, L. Magnib and E. Creaco, "Stability and robustness of real-time pressure control in water distribution systems," Journal of Hydraulic Engineering, vol. 146, no. 4, pp. 1-17, 2020.

[5] A. Lakehal and F. Laouacheria, "A bayesian approach to predicting water supply and rehabilitation of water distribution networks," International Journal of Advanced Computer Science and Applications, vol. 7, no. 12, pp. 99-106, 2016.

[6] A. Sniders and T. Komass, "Invariant method of load independent pressure control in steam boiler," Electrical Control, and Communication Engineering, vol. 1, no. 1, pp. 5-10, 2012.

[7] A. Venuprasad and Y. S. Narayan, "Automatic monitoring and controlling of pressure using PLC and SCADA," International Journal of Innovative Research in Science, Engineering and Technology, vol. 5, no. 7, pp. 1367113677, 2016.

[8] J. Ye, "PID tuning method using single-valued neutrosophic cosine measure and genetic algorithm," Intelligent Automation and Soft Computing, vol. 25, no. 1, pp. 15-23, 2019.

[9] J. M. Valenzuela, R. P. Alcocer, M. G. Medina and A. Dzul, "Nonlinear PID-type controller for quadrotor trajectory tracking," IEEE/ASME Transactions on Mechatronics, vol. 23, no. 5, pp. 2436-2447, 2018.

[10] J. G. Avila, C. Villaseñor, J. H. Barragan, N. A. Daniel, A. Y. Alanis et al., "Neural PD controller for an unmanned aerial vehicle trained with extended kalman filter," Algorithms, vol. 13, no. 2, pp. 1-18, 2020.

[11] Z. Civelek, M. Lüy, E. Çam and N. Barış̧̧1, "Control of pitch angle of wind turbine by fuzzy PID controller," Intelligent Automation and Soft Computing, vol. 22, no. 3, pp. 463-471, 2015.

[12] W. Wang and X. Z. Gao, "A single neuron PID controller based on immune tuning and it's application," in Sixth Int. Conf. on Natural Computation, Yantai, China, pp. 2831-2836, 2010.

[13] C. L. Franco, J. G. Avila, A. Y. Alanis, N. A. Daniel and C. Villaseñor, "Visual servoing for an autonomous hexarotor using a neural network based PID controller," Sensors, vol. 17, no. 8, pp. 1-17, 2017.

[14] O. A. Mejía and R. T. Olvera, Parameter Tuning of a PID Controller with Reactive Bio-Inspired for PMSM. Ixtapa, Mexico: IEEE International Autumn Meeting on Power, Electronics and Computing, 2018.

[15] O. A. Mejía, R. T. Olvera, A. V. González and I. R. Cambero, "Adaptive neural network control of chaos in permanent magnet synchronous motor," Intelligent Automation and Soft Computing, vol. 22, no. 3, pp. 1-9, 2016.

[16] J. M. Valenzuela, C. A. Avelar, S. P. Guzmán and V. Santibáñez, "Two adaptive control strategies for trajectory tracking of the inertia wheel pendulum: Neural networks vis à vis model regressor," Intelligent Automation and Soft Computing, vol. 23, no. 1, pp. 1-11, 2017.

[17] S. Jung, "Stability analysis of reference compensation technique for controlling robot manipulators by neural network," International Journal of Control, Automation and Systems, vol. 15, no. 2, pp. 952-958, 2017.

[18] C. M. Lin and H. Y. Li, "TSK fuzzy CMAC-based robust adaptive backstepping control for uncertain non-linear systems," IEEE Transactions on Fuzzy Systems, vol. 20, no. 6, pp. 1147-1154, 2012.

[19] T. Q. Ngo and V. P. Ta, "Robust adaptive self-organizing wavelet fuzzy CMAC tracking control for deicing robot manipulator," International Journal of Computers Communication \& Control, vol. 10, no. 4, pp. 567-578, 2015.

[20] V. P. Ta, X. K. Dang and T. Q. Ngo, "Adaptive tracking control based on CMAC for non-linear systems," in Proc. of the Int. Conf. on System Science and Engineering,, Ho Chi Minh City, Vietnam, pp. 494-498, 2017.

[21] V. P. Ta and X. K. Dang, "An innovative recurrent cerebellar model articulation controller for piezo-driven micromotion stage," International Journal of Innovative Computing, Information and Control, vol. 14, no. 4, pp. 1527 $1535,2018$.

[22] I. A. Bahadly, "Energy saving with variable speed drives in industry applications," in Proc. of the 2007 WSEAS Int. Conf. on Circuits, Systems, Signal and Telecommunications, Gold Coast, Australia, pp. 53-58, 2007.

[23] G. V. Palomo and J. A. Rossiter, "Programmable logic controller implementation of an auto-tuned predictive control based on minimal plant information," Elsevier, vol. 50, no. 1, pp. 92-100, 2011.

[24] C. Parrott and G. K. Venayagamoorthy, Real-Time Implementation of Intelligent Modeling and Control Techniques on a PLC Platform. Edmonton, AB, Canada: IEEE Industry Applications Society, pp. 1-7, 2008. 
[25] M. Bahita, "Neural stable adaptive control for a class of non-linear systems," Journal of Engineering Science and Technology, vol. 7, no. 1, pp. $97-118,2012$.

[26] X. K. Dang and V. P. Ta, "Robust recurrent cerebellar model articulation controller for non-linear mimo systems," International Journal of Advanced Computer Science and Applications, vol. 10, no. 3, pp. 38-47, 2019.

[27] L. Behera, S. Kumar and A. Patnaik, "On adaptive learning rate that guarantees convergence in feedforward networks," IEEE Transactions on Neural Networks, vol. 17, no. 5, pp. 1117- 1125, 2006.

[28] C. M. Lin and H. Y. Li, "A novel adaptive wavelet fuzzy cerebellar model articulation control system design for voice coil motors," IEEE Transactions on Industrial Electronics, vol. 59, no. 4, pp. 2024-2033, 2012.

[29] S. C. Pereira, A. S. Caporali and I. R. S. Casella, "Power line communication technology in industrial networks," in 2015 IEEE Int. Symp. on Power Line Communications and Its Applications, Austin, TX, USA, pp. 216-221, 2015.

[30] W. S. Ocaña, Ó. Proaño, P. Salazar, E. Salazar, W. Loza et al., "Distributed system SCADA using multiple industrial communication protocols on allen bradley equipment," Indian Journal of Science and Technology, vol. 12, no. 14, pp. 1-6, 2019. 